University of Wollongong

Research Online

Faculty of Engineering and Information

Faculty of Engineering and Information

Sciences - Papers: Part B

Sciences

2017

Exploring Student Interest of Online Peer Assisted Learning Using MixedReality Technology

Sasha Nikolic

University of Wollongong, sasha@uow.edu.au

Benjamin Nicholls

University of Wollongong

Follow this and additional works at: https://ro.uow.edu.au/eispapers1

Part of the Engineering Commons, and the Science and Technology Studies Commons

Research Online is the open access institutional repository for the University of Wollongong. For further information contact the UOW Library: research-pubs@uow.edu.au 


\title{
Exploring Student Interest of Online Peer Assisted Learning Using Mixed-Reality Technology
}

\author{
Abstract \\ Supplementary Instruction, also known as Peer Assisted Study Sessions (PASS), is a popular program \\ supporting the educational development of students in a collaborative setting. Flexibility of delivery has \\ been explored for a number of reasons including: work and family commitments; distance from campus; \\ and integrating regional and transnational satellite campuses. Previous studies have found attempts to \\ undertake online delivery of PASS lacking in student interest and have been restrained by the technology. \\ This study attempts to build upon this research by investigating student interest and the suitability of \\ using a mixed reality technology called iSee, based on video avatars within a 3D virtual world. Consistent \\ with previous studies student interest was low, converting a planned quasi-experimental study into a \\ simulation. The simulation suggests that the technology was suitable for online collaboration, with \\ effective communication of course content between participants and a good sense of presence. This \\ suggests this trial may gain greater student interest if undertaken within institutions offering \\ predominantly online, distance education.

\section{Disciplines} \\ Engineering | Science and Technology Studies

\section{Publication Details} \\ S. Nikolic \& B. Nicholls, "Exploring Student Interest of Online Peer Assisted Learning Using Mixed-Reality \\ Technology," in Teaching and Learning in a Digital World: Proceedings of the 20th International \\ Conference on Interactive Collaborative Learning - Volume 1, 2017, pp. 48-54.
}




\title{
Exploring Student Interest of Online Peer Assisted Learning using Mixed-Reality Technology
}

Sasha Nikolic and Benjamin Nicholls

\begin{abstract}
Supplementary Instruction, also known as Peer Assisted Study Sessions (PASS), is a popular program supporting the educational development of students in a collaborative setting. Flexibility of delivery has been explored for a number of reasons including: work and family commitments; distance from cam-pus; and integrating regional and transnational satellite campuses. Previous studies have found attempts to undertake online delivery of PASS lacking in student interest and have been restrained by the technology. This study attempts to build upon this research by investigating student interest and the suitability of using a mixed reality technology called iSee, based on video avatars within a 3D virtual world. Consistent with previous studies student interest was low, converting a planned quasi-experimental study into a simulation. The simulation suggests that the technology was suitable for online collaboration, with effective communication of course content between participants and a good sense of presence. This suggests this trial may gain greater student interest if undertaken within institutions offering predominantly online, distance education.
\end{abstract}

Keywords: collaborative learning; iSee; online learning; PASS; peer learning; mixed-reality; supplementary instruction

\section{Introduction}

Government reforms, accreditation bodies and university strategic plans have continued to focus on the importance of universities to provide students a quality education. One approach used to enhance the learning experience is by providing Supple-mental Instruction (SI), used by over 1000 higher education institutions across 29 countries [1]. The administration, structure and name of SI varies across institutions but the core focus of all programs is to improve student retention and learning out-comes through the facilitation of peer-learning; predominantly with senior students supporting junior students [2]. Within Australia, $\mathrm{SI}$ is known as Peer Assisted Study Sessions (PASS) with the benefits to student achievement well documented [3]. A review of research conducted by Dawson et al. [4] established three distinct benefits of PASS: students who participate in PASS receive higher grades; students regardless of ethnicity or prior academic achievement are more likely to succeed and at a higher rate; students persist at the institution at a higher rate. The key to a successful SI/PASS program are student leaders with strong technical, interpersonal and collaborative skills [5]; with the importance of capable leaders also identified in other teaching roles [6]. While face to face learning experiences remain popular, advancements in information technology has led to the greater adoption and exploration of e-learning and blended learning possibilities [7].

Online forms of PASS are at a fairly experimental stage investigating a range of technologies and approaches and have been labelled with many names such as ePAL, OPAL, OPTEN, PALS Online and PTEN [8]. Online versions of PASS provide the opportunity to increase flexibility, especially for 
students that do not live close to campus or providing a link with regional and transnational campuses. Within the various studies, an interest has been to investigate the differences in student engagement and collaboration between the face to face and online versions. This study closely aligns with the work of Beaumont et al. [3] testing the implementation of an Online Peer Assisted Learning (OPAL) scheme at the University of Melbourne across the faculties of Business and Economics and Engineering. The study used Adobe Connect as the platform and found that due to technology issues video and voice was rarely used and communication centered on text based chat, using whiteboards, and uploaded documents. This approach allow for anonymity which gave students greater confidence to participate. However, this led to greater temptation towards distraction, less personal contact and reduced social aspects associated with PASS hampering collaboration. In turn, participation for OPAL was low and it was recommended that this approach might be more suitable for institutions offering predominantly online, distance education.

An alternative to classical 2D web based collaboration are new 3D video augmented technologies blending video avatars with virtual environments. A pilot study by Nikolic et al. [9] compared the differences in team meetings between Adobe Connect and iSee (a mixed-reality platform). The study found students thought iSee was easier to use due to its similarities with gaming and that team collaboration was better due to the focus of face to face communication. This was followed up by a number of other studies [10-12] that found that the video avatar substantially contributed to the acceptance and quality of engagement online; and provided a mechanism to facilitate transnational education. Therefore, this pilot study investigates if iSee is a suitable technology for running a virtual PASS (V-PASS) scheme at a traditional face to face university that could then be expanded to include students from other trans-national satellite campuses.

\section{Design}

This pilot study was undertaken in a second year signal and systems engineering course at an Australian university that had been historically supported by PASS. The student cohort comprised of 86 local and 25 international students. The original intention was to undertake a quasi-experimental design as outlined in [3] to compare both student experience and learning between a PASS control group and a V-PASS experimental group.

The V-PASS sessions were conducted by the second author who had undertaken PASS classes as a student and worked together with the PASS leader to replicate the V-PASS experience. However, he was not an accredited PASS leader going through the required training programs. This was suitable for the small scale pilot and an ac-credited PASS leader would be required if the study was expanded. A virtual world was created for use within the iSee platform. The virtual world was designed to con-form to Jonassen's model [13] for constructivist learning environments (CLE) with three core components; context, representation and manipulation. Area one, marked out in Figure 1 , outlines the central hub consisting of multiple interactive boards for students use and one large board for the V-PASS leader to relay information. Areas two, three and four were designed as break out areas with interactive boards allowing students to work in small groups. 


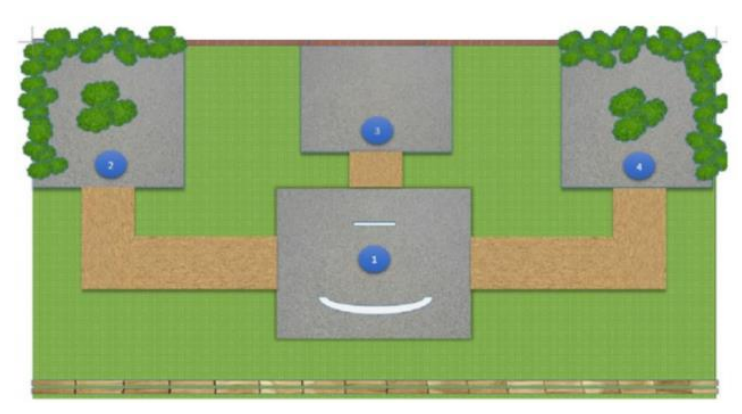

Fig. 1. Top down perspective of map concept design

The research study was initially promoted via a presentation during the lecture. From a pool of 111 students 34 registrations to participate in the study were received. The registered students were provided with all documentation required for ethics approval and instructions on how the V-PASS sessions would take place.

\section{Results \& Discussion}

Despite the use of a technology built for enhanced collaboration, student participation was poor, similar to the findings in [3]. Only two students participated in the first week of scheduled V-PASS sessions. In contrast, PASS on average had 7 students attend each session. This was followed up with another presentation in the lecture, and advertising channelled through student social media and the PASS leader. Attempts were also made to schedule V-PASS at times most desirable for students and to run session throughout the week. This effort resulted in only another two students thus eliminating the possibility of a sound experimental design. It was revealed that the students participating were also attending PASS at the same time. A survey was conducted in a PASS session to try and understand the reason for such low participation. A total of 4 responses were received from 7 students. Three of the four students clearly labelled that their preference was for direct face to face contact rein-forcing the findings in [3] that such online approaches might be best suited to institutions offering predominately online, distance education compared to traditional face to face universities.

An alternative approach was required to test the suitability of using iSee. A simulated V-PASS session was advertised to all students across the four year engineering degree via social media. A simulation does not accurately represent V-PASS participation due to a change in dynamics of the participants. Self-selection and the impact this has on the findings is a further limitation. However, the simulation can provide an estimate of the possible effectiveness of the technology that could lead to further studies. A total of 15 students from third and fourth year accepted to participate in an hour long VPASS simulation. An example of how the students appeared within the simulation can be seen in Figures 2 and 3 representing how students see each other within the 3D world and how they can interactive with learning materials. A survey instrument adapted from Bower et al. [14] was used to measure the simulated experience using a Likert scale from 1-Strongly Disagree to 5-Strongly Agree. The survey questions, mean responses and standard deviation are shown in Table 1. 


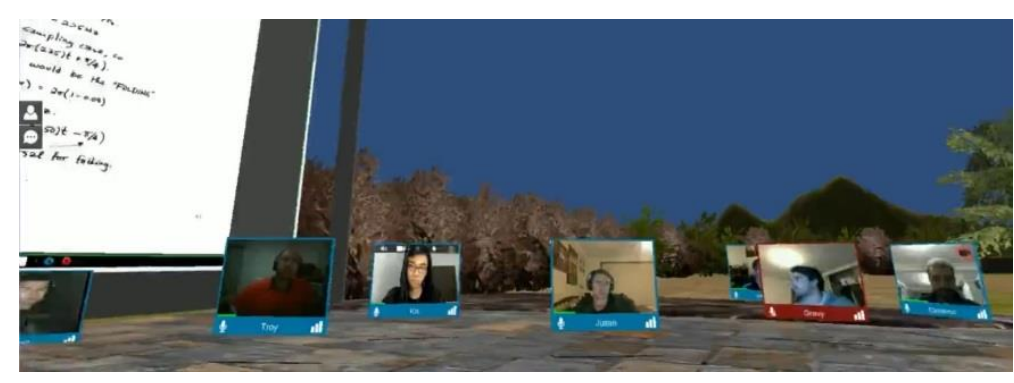

Fig. 2. Student discussion within iSee

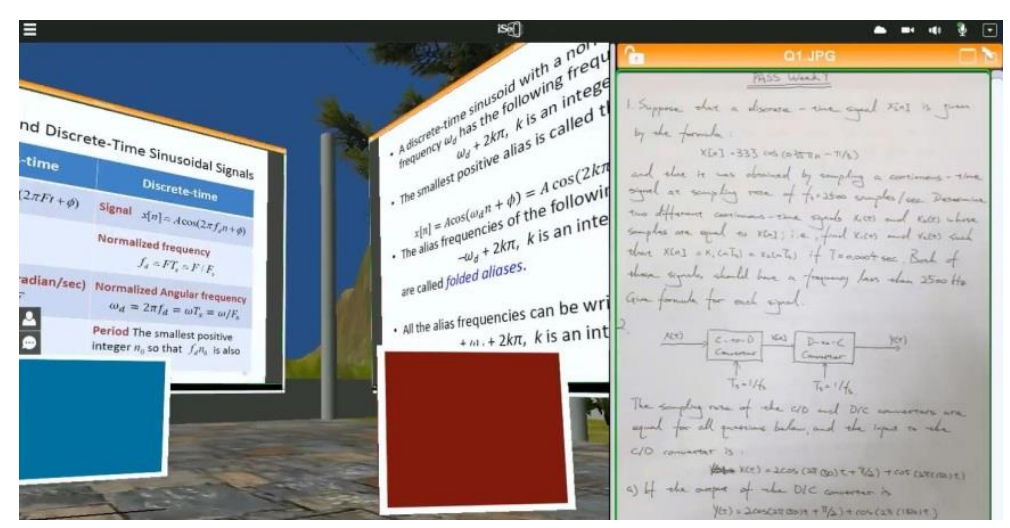

Fig. 3. Students working with interactive boards and reviewing notes

Table 1. Mean Responses from Simulated V-PASS Participants

\begin{tabular}{|c|l|c|c|}
\hline No. & \multicolumn{1}{|c|}{ Question } & Mean & $\begin{array}{c}\text { Standard } \\
\text { Deviation }\end{array}$ \\
\hline 1 & $\begin{array}{l}\text { The chat tool was an effective way of communicating with } \\
\text { other V-PASS participants }\end{array}$ & 4.07 & 0.27 \\
\hline 2 & $\begin{array}{l}\text { Verbal discussion was an effective way of communicating with } \\
\text { other participants }\end{array}$ & 4.40 & 0.63 \\
\hline 3 & $\begin{array}{l}\text { Being able to see other participants via a video avatar gave me } \\
\text { a strong sense of presence }\end{array}$ & 3.93 & 1.34 \\
\hline & $\begin{array}{l}\text { Being able to manipulate (move) my avatar allowed me to } \\
\text { interact with other participants more freely than a standard } \\
4\end{array}$ & PASS class & 3.33 \\
\hline 5 & $\begin{array}{l}\text { The interactive whiteboards were useful in conveying course } \\
\text { related information }\end{array}$ & 3.87 & 1.29 \\
\hline 6 & $\begin{array}{l}\text { The virtual learning space provided opportunities for } \\
\text { discourse/collaboration with other V-PASS participants }\end{array}$ & 4.07 & 0.70 \\
\hline 7 & $\begin{array}{l}\text { The virtual learning space allowed me to find and source } \\
\text { course related information effectively }\end{array}$ & 4.07 & 1.03 \\
\hline 8 & $\begin{array}{l}\text { I was able to effectively indicate my status to others (e.g. } \\
\text { wanting attention, agreeing, being unsure, etc.) }\end{array}$ & 3.60 & 0.91 \\
\hline 9 & I felt like I was present with my peers during V-PASS & 3.93 & 0.96 \\
\hline 10 & $\begin{array}{l}\text { The software provided clear and accurate representation of } \\
\text { information and people }\end{array}$ & 3.80 & 1.01 \\
\hline 11 & The software enable collaboration to occur & 4.07 & 0.80 \\
\hline 12 & $\begin{array}{l}\text { V-PASS classes are an effective method of teaching course } \\
\text { related content }\end{array}$ & 4.20 & 0.86 \\
\hline 13 & The idea of a V-PASS class is appealing & 4.47 & 0.92 \\
\hline
\end{tabular}

While no concrete findings can be determined by the simulation, the mean score across all questions was 3.98, indicating an 'agree' across the board suggesting that iSee may be a suitable technology for running V-PASS sessions. In particular Q2 indicates that the platform is effective for verbal communication, one of the key limitations in [3]. The responses show that the participants believed that V-PASS provided a good sense of presence, allowed collaboration to occur and was an effective 
way of teaching course related content, providing some agreement with the findings in [10-12]. This does provide some confidence in using iSee to trial a transnational V-PASS session if a way to encourage student participation could be found. The best investigation to understand if iSee can improve student interest in V-PASS would require repeating this study at a predominately online university.

\section{Conclusion}

This study implemented a pilot program to test the suitability of using a mixed reality technology, using video based avatars, to run a virtual PASS program. The study found that students had very little interest in considering a V-PASS opportunity, con-firming the findings of similar studies using different technologies [8]. The evidence continues to suggest that students at traditional universities have a preference for face to face learning opportunities regardless of the benefits and flexibility associated with a V-PASS program [3]. Consequently, the study was transformed into a simulation activity to gain an estimate of the suitability of using the mixed reality technology, iSee. Students that did participate in the simulated activity expressed that the iSee technology was suitable for online collaboration, with effective communication of course content between participants and a good sense of presence. The next stage of the project will be to test the interest of running V-PASS between PASS leaders at the main campus with students from a satellite campus.

\section{References}

1. Power Ms, C. (2010). Peer Assisted Study Sessions (PASS): through a complexity lens. Journal of Peer Learning, 3(1), 1-11.

2. Birch, E., \& Li, I. (2009). The Impact of Peer Assisted Study Sessions on Tertiary Academ-ic Performance. Paper presented at the Quantitative Analysis of Teaching and Learning in Higher Education in Business, Economics and Commerce: Forum Proceedings

3. Beaumont, T. J., Mannion, A. P., \& Shen, B. O. (2012). From the campus to the cloud: the online peer assisted learning scheme. Journal of Peer Learning, 5(1), 1-15.

4. Dawson, P., van der Meer, J., Skalicky, J., \& Cowley, K. (2014). On the effectiveness of supplemental instruction: A systematic review of supplemental instruction and peer-assisted study sessions literature between 2001 and 2010. Review of Educational Research, 84(4), 609-639.

5. Stout, M. L., \& McDaniel, A. J. (2006). Benefits to supplemental instruction leaders. New Directions for Teaching and Learning, 2006(106), 55-62.

6. Nikolic, S., Suesse, T., McCarthy, T., \& Goldfinch, T. (In Press). Maximising Resource Al-location in the Teaching Laboratory: Understanding Student Evaluations of Teaching Assis-tants in a Team Based Teaching Format. European Journal of Engineering Education.

7. Zhang, Y., Dang, Y., \& Amer, B. (2016). A Large-Scale Blended and Flipped Class: Class Design and Investigation of Factors Influencing Students Intention to Learn. IEEE Transac-tions on Education, 59(4), 263-273. doi:10.1109/TE.2016.2535205 8. Watts, H., Malliris, M., \& Billingham, O. (2015). Online Peer Assisted Learning: Reporting on practice. Journal of Peer Learning, 8(1), 85-104

9. Nikolic, S., Lee, M. J. W., \& Vial, P. J. (2015). 2D versus 3D collaborative online spaces for student team meetings: comparing a web conferencing environment and a video-augmented virtual world. Paper presented at the 26th Annual Conference of the Australasian Association for Engineering Education, Geelong.

10. Lee, M. J. W., Nikolic, S., Vial, P. J., Ritz, C., Li, W., \& Goldfinch, T. (2016). Enhancing project-based learning through student and industry engagement in a video-augmented 3D virtual trade fair. IEEE Transactions on Education, 59(4), 290 298. doi:10.1109/TE.2016.2546230

11. Nikolic, S., Lee, M. J. W., Goldfinch, T., \& Ritz, C. H. (2016). Addressing Misconceptions about Engineering through Student-Industry Interaction in a Video-Augmented 3D Im-mersive Virtual World. Paper presented at the Frontiers in Education Conference (FIE)

12. Nikolic, S., \& Li, W. (2016, 7-9 Dec. 2016). Facilitating student and staff engagement across multiple offshore campuses for transnational education using an immersive video augmented learning platform. Paper presented at the 2016 IEEE International Conference on Teaching, Assessment, and Learning for Engineering (TALE).

13. Jonassen, D. H. (1999). Designing constructivist learning environments. Instructional de-sign theories and models: A new paradigm of instructional theory, 2, 215-239.

14. Bower, M., Kennedy, G. E., Dalgarno, B., Lee, M. J. W., \& Kenney, J. (2014). Blended synchronous learning: A handbook for educators 